\title{
PAPERS
}

\section{Reactive oxygen species activity and lipid peroxidation in Helicobacter pylori associated gastritis: relation to gastric mucosal ascorbic acid concentrations and effect of $H$ pylori eradication}

\author{
I M Drake, N P Mapstone, C J Schorah, K L M White, D M Chalmers, M F Dixon, \\ A T R Axon
}

\begin{abstract}
Background-Helicobacter pylori is an independent risk factor for gastric cancer, and this association may be due to the bacterium causing reactive oxygen species mediated damage to DNA in the gastric epithelium. High dietary ascorbic acid intake may protect against gastric cancer by scavenging reactive oxygen species.

Aims-To assess reactive oxygen species activity and damage in gastric mucosa in relation to gastric pathology and mucosal ascorbic acid level, and to determine the effect of $H$ pylori eradication on these parameters.

Patients-Gastric biopsy specimens were obtained for analysis from 161 patients undergoing endoscopy for dyspepsia.

Methods-Reactive oxygen species activity and damage was assessed by luminol enhanced chemiluminescence and malondialdehyde equivalent estimation respectively. Ascorbic acid concentrations were measured using HPLC.

Results-Chemiluminescence and malondialdehyde levels in gastric mucosa were higher in patients with $H$ pylori gastritis than in those with normal histology. Successful eradication of the bacterium led to decreases in both parameters four weeks after treatment was completed. Gastric mucosal ascorbic acid and total vitamin $C$ concentrations were not related to mucosal histology, but correlated weakly with reactive oxygen species activity (chemiluminescence and malodialdehyde levels).

Conclusions-Data suggest that reactive oxygen species play a pathological role in $H$ pylori gastritis, but mucosal ascorbic acid is not depleted in this condition. (Gut 1998;42:768-771)
\end{abstract}

Keywords: Helicobacter pylori; gastric cancer; reactive oxygen species; ascorbic acid

There is increasing interest in the pathological role of reactive oxygen species (ROS) in diseases where inflammation is a major feature such as rheumatoid arthritis ${ }^{1}$ and inflammatory bowel disease. ${ }^{2}$ Longstanding ulcerative colitis is a premalignant condition and ROS may play a part in the carcinogenic process. In vitro work has shown that ROS can cause a variety of DNA lesions $\mathrm{s}^{3-5}$ and produce mutations in bacterial $^{6-8}$ and mammalian cells. ${ }^{9-12}$ ROS can also induce malignant transformation in cultured fibroblast cell lines. ${ }^{13}$

Helicobacter pylori infection is now recognised as an independent risk factor for gastric cancer $^{14-16}$ and has been designated a class I carcinogen by an IARC-WHO ${ }^{17}$ committee. ROS production in association with this bacterium has been shown to occur in vitro ${ }^{18}$ and in vivo. ${ }^{192}$ ROS may play a part in $H$ pylori associated gastric carcinogenesis, and it is of interest that epidemiological studies suggest a protective role for dietary ascorbic acid, ${ }^{21}{ }^{22} \mathrm{a}$ chemical known to be a good scavenger of ROS. $^{23} 24$

The presence of ROS in $H$ pylori infection has so far been determined using luminol or lucigenin enhanced chemiluminescence. Although this method shows ROS to be present, it does not necessarily follow that they are responsible for tissue damage or play a pathological role.

In this study we have used the measurement of gastric mucosal malondialdehyde equivalent concentrations to assess oxidative damage to lipids, comparing the results of this technique with the luminol enhanced chemiluminescence findings in order to determine whether ROS could play a pathological role in $H$ pylori infection. We have also measured mucosal ascorbic acid concentrations in order to study whether ROS generation affects levels of this vitamin, as it has previously been observed that concentrations of ascorbic acid in gastric juice are lower in the presence of chronic gastritis..$^{25}$

Patients and methods

Patients were recruited from those undergoing upper gastrointestinal endoscopy for dyspepsia in our unit. Local ethics committee permission was granted and informed consent obtained in all cases. 
Table 1 Antral chemiluminescence and malondialdehyde and vitamin C concentrations according to histological diagnosis

\begin{tabular}{lccll}
\hline Histological findings & Chemiluminescence (cpm/mg) & Malondialdehyde (nmol/g) & $\begin{array}{l}\text { Ascorbic acid } \\
(\mu \mathrm{mol} / \mathrm{kg})\end{array}$ & $\begin{array}{l}\text { Total vitamin C } \\
(\mu \mathrm{mol} / \mathrm{kg})\end{array}$ \\
\hline $\begin{array}{l}\text { Normal }(\mathrm{n}=53) \\
\begin{array}{l}\text { Reactive gastritis } \\
(\mathrm{n}=31)\end{array}\end{array}$ & $1210(467-2891)$ & $78.9(62.2-97.4)$ & $441(303-674)$ & $553(400-727)$ \\
$\begin{array}{l}\text { H pylori } \text { gastritis }(\mathrm{n}=77) \\
\text { p }\end{array}$ & $23885(4908-47864)^{\star}$ & $112.3(81.4-147.8)^{\star}$ & $582(347-757)$ & $672(394-840)$ \\
\hline
\end{tabular}

Values are expressed as median (interquartile range).

${ }^{\star} \mathrm{p}<0.0001 v$ normal histology (Mann-Whitney U test).

At endoscopy, nine antral biopsy specimens and two corpus biopsy specimens were taken. Two antral specimens were used for luminol enhanced chemiluminescence and two assayed for malondialdehyde equivalent concentrations. A further two antral and two corpus biopsy specimens were examined histologically using haematoxylin and eosin, and a modified Giemsa stain to detect $H$ pylori. In addition, one antral biopsy specimen was used for urease testing (CLO test) and a further specimen sent for $H$ pylori culture. Finally, one antral biopsy specimen was used for mucosal total vitamin C (ascorbic acid + dehydroascorbic acid) and ascorbic acid concentration measurement using high performance liquid chromatography (HPLC).

\section{CHEMILUMINESCENCE}

Biopsy specimens were transported in phosphate buffered saline and assayed within three hours. After weighing, each specimen was added to a precounted scintillation vial containing $1 \mathrm{ml}$ of $75 \mu \mathrm{mol}$ luminol solution and counted for five minutes in a liquid scintillation counter set in the "out of coincidence" mode. The mean of the two biopsy specimens was then calculated in each case.

MALONDIALDEHYDE EQUIVALENT ESTIMATION Biopsy specimens were stored at $-70^{\circ} \mathrm{C}$ and assayed by a modification of the procedure of Yagi. ${ }^{27}$ Briefly each sample was blot dried, weighed and added to $4 \mathrm{ml}$ of water. One $\mathrm{ml}$ of thiobarbituric acid solution, made by dissolving $167 \mathrm{mg}$ of thiobarbituric acid in a mixture of $25 \mathrm{ml}$ of water and $25 \mathrm{ml}$ of glacial acetic acid, was then added to each sample. A set of malondialdehyde standards was also freshly prepared and added to $1 \mathrm{ml}$ of thiobarbituric acid solution in the same way. After mixing, all samples and standards were heated at $100^{\circ} \mathrm{C}$ for one hour. Samples and standards were cooled on ice and the malondialdehyde (MDA) equivalents extracted by adding $5 \mathrm{ml}$ of butanl-ol to each. Each tube was centrifuged at 1200 $g$ for 10 minutes to separate the aqueous and organic phases and the fluorescence of the butan-1-ol phase was then read at an excitation of $515 \mathrm{~nm}$ and emission of $555 \mathrm{~nm}$ and compared with the fluorescence of the MDA standards. Duplicate samples were assayed for each subject and the average used. Measurements could be made with adequate precision down to $40 \mathrm{nmol} / \mathrm{g}$ of tissue with a blot dried weight of $1 \mathrm{mg}$ of tissue, although weights were always above this and averaged $2 \mathrm{mg}$. The interassay coefficient of variation (precision) of the method was $10.1 \%$.
TOTAL VITAMIN C AND ASCORBIC ACID MEASUREMENT

Biopsy specimens were stored in liquid nitrogen and assayed within two weeks. After thawing, the samples were blotted dry, then weighed. They were homogenised in $0.5-1.0$ $\mathrm{ml}$ of $2 \%$ metaphosphoric acid and divided into two parts. Dithiothreitol was added to one part to a final concentration of $6 \mathrm{mg} / \mathrm{ml}$ for total vitamin $\mathrm{C}$ estimation. Both parts were centrifuged at $2000 \mathrm{~g}$, and the supernatant analysed by HPLC using reverse phase ion pair chromatography on a C18 column. ${ }^{28}{ }^{28}$ Ascorbic acid was selectively measured using an electrochemical detector set at low voltage. Total vitamin $\mathrm{C}$ was estimated as ascorbic acid by incubating the sample containing dithiothreitol at $45^{\circ} \mathrm{C}$ for 120 minutes prior to analysis by HPLC in order to reduce any dehydroascorbic acid to ascorbic acid.

\section{STATISTICS}

Non-parametric tests were used. Unpaired data were compared using the Mann-Whitney test, and paired data with the Wilcoxon matched pairs, signed ranks test. Correlations were calculated using the Spearman rank test, and analysis of variance made with the Kruskal-Wallis test.

\section{Results}

There were 161 patients in the study with a mean age of 47 years (range 20-79) of whom 105 were male and 56 were female. Of these, 77 had $H$ pylori associated chronic gastritis, 53 normal histology, and 31 reactive gastritis. The mean age (and age range) were as follows: $H$ pylori associated gastritis 51 years (22-75), normal 40 years (20-69), and reactive gastritis 45 years (25-79). Of the $H$ pylori gastritis patients, $31(40 \%)$ smoked, compared with 15 $(28 \%)$ in the normal group, and seven $(23 \%)$ in the reactive gastritis group.

Chemiluminescence and MDA equivalent levels were higher $(\mathrm{p}<0.0001)$ in the mucosa of patients with $H$ pylori associated chronic gastritis than in those with normal histology (table 1). There was no significant difference in the concentration of either of these indexes between patients with reactive gastritis and those with normal histology $(p=0.70, p=0.59$ respectively).

Patients with $H$ pylori gastritis were graded according to the Sydney classification. Chemiluminescence varied significantly between grades 1 and 3 of inflammation (KruskalWallis, $\mathrm{p}<0.05)$ with levels being significantly higher in samples with inflammatory scores of 2 compared with those with scores of 1 
Table 2 Effect of successful H pylori eradiation treatment $(n=22)$ on chemiluminescence and malondialdehyde and vitamin $C$ concentrations in antral biopsy samples

\begin{tabular}{llc}
\hline & Before eradiation & After eradication \\
\hline Chemiluminescence $(\mathrm{cpm} / \mathrm{mg})$ & $16103(8810-478644)$ & $1441(646-3979)^{\star \star \star}$ \\
Malondialdehyde $(\mathrm{nmol} / \mathrm{g})$ & $122.3(84.7-135.8)$ & $98.9(70.9-144.6)^{\star \star}$ \\
Ascorbic acid $(\mu \mathrm{mol} / \mathrm{kg})$ & $544(341-761)$ & $563(347-693)$ \\
Total vitamin $\mathrm{C}(\mu \mathrm{mol} / \mathrm{kg})$ & $665(406-854)$ & $472(325-715)$ \\
\hline
\end{tabular}

Values are expressed as median (interquartile range).

${ }^{\star \star} \mathrm{p}<0.01$ and ${ }^{\star \star \star} \mathrm{p}<0.001 v$ before eradication (Wilcoxon).

Table 3 Effect of unsuccessful H pylori eradiation treatment $(n=17)$ on chemiluminescence and malondialdehyde and vitamin $C$ concentrations in antral biopsy samples

\begin{tabular}{llc}
\hline & Before eradiation & After eradication \\
\hline Chemiluminescence $(\mathrm{cpm} / \mathrm{mg})$ & $30301(12112-54921)$ & $10822(2348-29006)$ \\
Malondialdehyde $(\mathrm{nmol} / \mathrm{g})$ & $108.0(85.1-143.1)$ & $101.4(81.2-109.4)$ \\
Ascorbic acid $(\mu \mathrm{mol} / \mathrm{kg})$ & $555(286-691)$ & $518(272-902)$ \\
Total vitamin $\mathrm{C}(\mu \mathrm{mol} / \mathrm{kg})$ & $618(382-897)$ & $608(306-910)$ \\
\hline
\end{tabular}

Values are expressed as median (interquartile range).

$(\mathrm{p}<0.05)$. There was also significant variation in chemiluminescence between activity scores (Kruskal-Wallis, $\mathrm{p}<0.05$ ) with levels being higher in samples with scores of 2 or 3 compared with those with scores of $0(p<0.05)$.

MDA equivalent concentrations did not vary significantly between different inflammation scores (Kruskal-Wallis, $\mathrm{p}=0.20$ ) but there was a trend for values to be greater in samples with higher activity scores (Kruskal-Wallis, $\mathrm{p}=0.07$ ) which reached significance in samples scored 2 or 3 compared with those with a score of 0 $(\mathrm{p}<0.05)$.

There were no significant differences in ascorbic acid concentrations in antral mucosa between any of the histological groups, and the same was true of antral mucosal total vitamin C levels (table 1).

MDA levels did not correlate with antral mucosal concentrations of ascorbic acid $(r=0.13, \mathrm{p}=0.08)$, but there was, however, a weak correlation with antral total vitamin C concentration $(r=0.15, p<0.05)$. In the case of chemiluminescence, there were weak correlations with antral ascorbic acid $(r=0.19$, $\mathrm{p}<0.05)$ and antral vitamin C $\quad(r=0.18$, $\mathrm{p}=0.05$ ).

Of the 77 patients with $H$ pylor $i$ infection, 39 agreed to have a further endoscopy four weeks after completing eradication treatment. Treatment was with a two week course of tripotassium dicitratobismuthate $120 \mathrm{mg}$ four times daily, tetracycline $500 \mathrm{mg}$ four times daily, and metronidazole $400 \mathrm{mg}$ three times daily. $H$ pylori was considered to be successfully eradicated if histology, culture, and urease testing were all negative for $H$ pylori at the follow up endoscopy. Using these criteria the $H$ pylori in 22 patients were successfully eradicated, and 17 patients still had $H$ pylori detected four weeks after treatment.

Antral levels of MDA and chemiluminescence both fell significantly in the successfully treated patients $(\mathrm{p}<0.01$ and $\mathrm{p}<0.001$ respectively; table 2), but there was no significant fall in MDA or chemiluminescence in those patients in whom eradication treatment had failed ( $p=0.37$ and $p=0.27$ respectively; table 3). Antral mucosal concentrations of ascorbic acid and total vitamin $\mathrm{C}$ did not change following eradication treatment, whether successful or not.

\section{Discussion}

We have shown increased chemiluminescence in the antral mucosa of patients with $H$ pylori associated chronic gastritis compared with those with normal histology. This confirms previous work. ${ }^{20}$ However, we have also shown that MDA concentrations are higher in the $H$ pylori associated chronic gastritis group. Since MDA production could reflect oxidative damage to lipids, this supports the hypothesis that ROS do play a pathological role in this condition. We found no difference in chemiluminescence or MDA levels in the mucosa of patients with reactive gastritis compared with those with normal histology. This is consistent with the view that ROS are produced primarily by neutrophils which are much more prominent in chronic gastritis than in reactive gastritis.

In the Sydney system activity scores reflect the degree of neutrophil infiltration and inflammatory scores are based on lymphocyte and plasma cell levels. The trends for increased chemiluminescence and MDA equivalent concentrations with higher activity grades are again consistent with neutrophils being the chief source of ROS in gastritis. The weaker statistical linking of MDA and chemiluminescence with inflammation scores is not surprising, as lymphocytes and plasma cells are thought to be less important as sources of ROS.

The importance of $H$ pylori as the initiating agent for neutrophil infiltration and subsequent ROS production is shown by our eradication results. MDA concentrations and chemiluminescence levels both fell significantly in the mucosa of patients in whom $\mathrm{H}$ pylori was successfully eradicated, but not in those in whom eradication treatment failed. Thus $H$ pylori infection is likely to be a cause of increased ROS generation and damage rather than an association.

MDA concentrations must always be interpreted with caution as lipid oxidation as a result of cell death from any cause can lead to increased MDA levels. However, cell proliferation (and presumably also cell death) is increased in the postsurgical stomach where biliary reactive gastritis is usual ${ }^{29}$; MDA levels were not however increased in our patients with reactive gastritis. This suggests that cell death is not an important source of MDA in this study and we believe that here, MDA levels are likely to be a reflection of oxidative changes occurring as a primary event leading to cell damage, rather than as a consequence of cell death. This is supported by the fact that MDA concentrations are correlated with chemiluminescence levels, when all 161 cases are taken together $(r=0.30, \mathrm{p}<0.001)$. As it is generally believed that luminol dependent chemiluminescence is a reliable measure of important $\operatorname{ROS}^{20}$ produced in the respiratory burst of granulocytes and macrophages, ${ }^{30} 31$ the correlation between chemiluminescence and MDA levels is further evidence that MDA reflects ROS mediated lipid peroxidation. 
We were unable to show any relation between the mucosal concentrations of ascorbic acid or total vitamin $\mathrm{C}$ and the histological findings. This confirms earlier work. ${ }^{28} 32$

The weak correlations between ROS activity (as measured by MDA and chemiluminescence) and antral concentrations of ascorbic acid or total vitamin $\mathrm{C}$ could constitute a type 2 error. If not, then it may be that concentrations of ascorbic acid (the active antioxidant component of vitamin C) are higher in the infected gastric mucosa either as a protective response to increased oxidative stress or because of the influx of inflammatory cells which contain higher vitamin $\mathrm{C}$ concentrations than those reported here for normal gastric mucosa. ${ }^{33}$ Whatever the explanation, the ascorbic acid/vitamin $\mathrm{C}$ data provide no support for the argument that an increase in mucosal ascorbic acid (for example by dietary manipulation) would be an effective way of reducing ROS damage as high levels are not depleted during increased ROS generation, suggesting that ascorbate is either not involved in quenching ROS, or that normal metabolism adequately sustains mucosal ascorbate reserves by rapid reduction of dehydroascorbic acid created by ROS oxidation of ascorbic acid. However, other antioxidant nutrients (for example, vitamin E, carotenoids) may be better at limiting such damage, but initial investigations suggest that like ascorbic acid, mucosal levels of these antioxidants are not affected by $H$ pylori associated gastritis. ${ }^{34}$

In conclusion, the findings suggest that ROS play a pathological role in $H$ pylori associated gastritis. If ROS are implicated in gastric carcinogenesis, eradication of $H$ pylori could reduce gastric cancer risk. If we accept that ROS could contribute to $H$ pylori mediated carcinogenesis, experimental work showing oxidative DNA damage in this condition is now needed.

We gratefully acknowledge the support of the Ivy Hobson Trust and the Kellogg Company. We wish to thank Miss Julie Mackintosh and Mrs Susan Trundle for typing the manuscript. Part of this work has been previously published in abstract form (Gut 1994;35(suppl 5):S3 and Am f Gastroenterol 1994;89:1357).

1 Rowley DA, Gutteridge JMC, Blake DR, et al. Lipid peroxidation in rheumatoid arthritis: thiobarbituric acid reactive material and catalytic iron salts in synovial fluid from rheumatoid patients. Clin Sci 1984;66:691-5.

2 Keshavarzian A, Sedghi S, Kanofski J, et al. Excessive Keshavarzian A, Sedghi S, Kanofski J, et al. Excessive
production of reactive oxygen metabolites by inflamed production of reactive oxygen metabolites by inflamed colon: analysis by chemil

3 Shacter E, Beecham EJ, Covey JM, et al. Activated neutrophils induce prolonged DNA damage in neighbouring cells. Carcinogenesis 1988;9:2297-304.

4 Schraufstatter I, Hyslop PA, Jackson JH, et al. Oxidant induced DNA damage of target cells. $\mathcal{F}$ Clin Invest 1988;82 1040-50.

5 Weitberg $\mathrm{AB}$, Weitzman SA, Destrempes $\mathrm{M}$, et al. Stimulated human phagocytes produced cytogenetic changes in cultured mammalian cells. N Engl f Med 1983;
6 Barak M, Ulizur S, Merzbach D. Phagocytosis induced mutagenesis in bacteria. Mutat Res 1983;121:7-16.

7 Farr SB, D'Ari R, Touati D. Oxygen dependent mutagenesi in E coli lacking SOD. Proc Natl Acad Sci USA 1986;83:8268-72.

8 Fulton AH, Lovelas SE, Heppner GH. Mutagenic activity of tumour associated macrophages in Salmonella typhimurium strains TA 98 and TA 100. Cancer Res 1984;44:4308-11.

9 Weitzman SA, Stossel TP. Phagocyte induced mutation in Chinese hamster ovary cells. Cancer Lett 1984;22:337-42.

$10 \mathrm{Hsie}$ AW, Reizo L, Katz S, et al. Evidence for reactive oxygen species inducing mutations in mammalian cells. Proc Natl Acad Sci USA 1986;83:9616-20.

11 Ziegler-Skylakis K, Andre U. Mutagenicity of hydrogen peroxide in V79 Chinese hamster cells. Mutat Res 1987;192 65-7.

12 Yamashina K, Miller B, Heppner GH. Macrophage mediated induction of drug resistant variants in a mouse mammary tumour cell line. Cancer Res $1986 ; 4$

13 Weitzman SA, Weitberg AB, Clark EP, et al. Phagocytes as carcinogens: malignant transformation prod

14 Forman D, Newell DG, Fullerton F. Association between infection with Helicobacter pylori and risk of gastric cancer: evidence from prospective investigation. BMF 1991;302:1302-5

15 Parsonnet J, Friedman GD, Vanderstern DP. Helicobacter pylori and the risk of gastric carcinoma. $N$ Engl f Med 1991;325:1127-31.

16 Nomura A, Stemmerman GN, Glyou PH. Helicobacter pylori infection and gastric carcinoma among Japanese Americans in Hawaii. N Engl f Med 1991;325:1132-6.

17 IARC-WHO. The evolution of carcinogenic risks in humans. Monograph 62. Lyon, France: International Agency for Research on Cancer, 1994

18 Rautelin H, Blonberg B, Fredlund H, et al. Incidence of Helicobacter pylori strains activating neutrophils in patients with peptic ulcer disease. Gut 1993;34:599-603.

19 Davies GR, Simmonds NJ, Stevens TRJ, et al. Mucosal reactive oxygen metabolite production in duodenal ulcer disease. Gut 1992;33:1467-72.

20 Davies GR, Simmonds NJ, Stevens TRJ, et al. Helicobacter pylori stimulates antral mucosal reactive oxygen metabolite production in vivo. Gut 1994;35:179-85.

21 Ramon JM, Serra-Majem L, Cerdo C, et al. Nutrient intake and gastric cancer risk: a case-controlled study in Spain. Int Epidemiol 1993;22:983-8.

22 Buiatti E, Palli D, Decorli A, et al. A case control study of gastric cancer and diet in Italy: II Association with nutrients. Int F Cancer 1990;45:896-901

23 Whitehead JP, Thorpe GHG, Masarell SRJ. Enhanced chemiluminescence assay for antioxidant capacity in
biological fluids. Analytical Chimica Acta 1992;266:265-77.

24 Frei B. Ascorbic acid protects lipids in human plasma and low density lipoprotein against oxidative damage. Am $\mathrm{f}$ Clin Nutr 1991;54:1113S-8S.

25 Sobala GM, Schorah CJ, Sanderson M, et al. Ascorbic acid in the human stomach. Gastroenterology 1989;97:357-63.

26 Sobala GM, Pignatelli B, Schorah CJ, et al. Levels of nitrite, nitrate, $\mathrm{N}$-nitroso compounds, ascorbic acid and total bile acids in gastric juice of patients with and without precancerous conditions of the stomach. Carcinogenesis 1991;12:193-8.

27 Yagi K. A simple fluorometric assay for lipoperoxide in blood plasma. Biochem Med 1976;15:212-16.

28 Waring AJ, Drake IM, Schorah CJ, et al. Ascorbic acid and total vitamin C concentrations in plasma, gastric juice and gastric intestinal mucosa: effects of gastritis and oral supplementation. Gut 1996;38:171-6.

29 Lynch DAF, Mapstone NP, Clarke AMT, et al. Cell proliferation in the gastric corpus in Helicobacter pylori associated gastritis and the post-surgical stomach. Gut 1994;35:S34.

30 Cadenas E, Sies H. Low level chemiluminescence as an indicator of singlet oxygen in biological systems. Methods Enzymol 1984;105:221-31.

31 Vilim V, Wilhelm J. What do we measure by a luminoldependent chemiluminescence of phagocytes? Free Radic Biol Med 1989;6:623-9.

32 Rathbone BJ, Johnson AW, Wyatt JI, et al. Ascorbic acid: a factor concentrated in human gastric juice. Clin $\mathrm{Sci}_{\mathrm{i}}$ 1989;76:237-41.

33 Schorah CJ. The transport of vitamin C and effects of disease. Proc Nutr Soc 1992;51:189-98.

34 Sanderson MJ, White KLM, Drake IM, et al. Vitamin E and carotenoids in gastric biopsies: the relation to plasma concentrations in patients with and without Helicobacter pylori gastritis. Am f Clin Nutr 1997;65:101-6. 